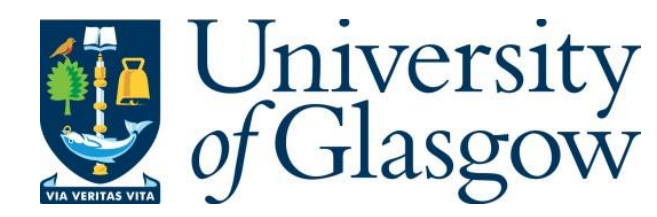

Tuckett, S. and Quinton, R. (2018) Looking back and moving forward: the MLitt in Dress and Textile Histories at the University of Glasgow. International Journal of Fashion Studies, 5(1), pp. 157-168. (doi:10.1386/infs.5.1.157_1)

There may be differences between this version and the published version. You are advised to consult the publisher's version if you wish to cite from it.

http://eprints.gla.ac.uk/152956/

Deposited on: 4 December 2017

Enlighten - Research publications by members of the University of Glasgow http://eprints.gla.ac.uk 


\title{
Looking Back and Moving Forward: the MLitt in Dress and Textile Histories at the University of Glasgow
}

\author{
Sally Tuckett (University of Glasgow) \\ Rebecca Quinton (University of Glasgow \& Glasgow Museums)
}

\section{Introduction}

In recent years, the state and reception of the fields of fashion studies and dress and textile history has been much debated. Conferences and workshops dedicated to assessing the role, status and future of these fields have highlighted examples of good practice in cross-institutional research, the popularity of fashion and/or dress exhibitions, and of the dynamic growth in undergraduate and postgraduate teaching in these areas (Cumming 2004: 9-10; McNeill 2010; Nicklas and Pollen 2015). The number of undergraduate and postgraduate courses offered in the UK alone demonstrate the continuing and increasing popularity of studying and understanding the design, use and history of clothing and, of course, fashion. ${ }^{1}$ Invariably, such expansion has necessitated the continued discussion on the importance of terminology with regards to terms such as 'costume', 'clothing', 'dress', 'fashion' and so forth (Taylor 2002: 44-65; Cumming 2004: 15-17; Taylor 2013: 24-27; Nicklas and Pollen 2015: 1-2). 'Fashion' in particular, for instance, is continually subject to changing definitions; its original connotations of modernity, change and western society expanding and evolving to include consideration of it as a global, non-western phenomenon (Francks 2015), and most recently, to debates such as those at the 2016 conference at Massey University in New Zealand, over whether 'fashion' as a concept and as a practice, might have reached its limit.

While such discussions can seem to be mere semantics on the surface, providers of higher education courses and degrees that come under the remit of fashion studies and/or dress history need to be cognisant of these debates and know where there are commonalities and differences. This is so that they are not only clear on what they are offering the students but also so they show these students how they in turn can participate in and contribute to this growing field. This article will therefore outline the history of the MLitt in Dress and Textile Histories at the University of Glasgow, a taught postgraduate, year-long programme that was established in $2011 .^{2}$ It will discuss how dress and textile histories are interpreted to include, but not be exclusive to, the notion of fashion, and how this manifests in the methodologies and ethos of the programme. It will also explore some of the challenges that it faces in providing support for students and graduates in an increasingly competitive market, challenges that are applicable to everyone on the fashion studies/dress history spectrum.

\section{Past: the MA at Winchester School of Art and University of Southampton, 1992-2009}

The MLitt in Dress and Textile Histories at the University of Glasgow is the successor to the MA in History of Textiles and Dress, which was established at the Winchester School of Art in $1992 ;^{3}$ the School subsequently became part of the University of Southampton in 1996. The Winchester MA aimed to encourage students to study the history of textiles in dress and furnishings from the eighteenth century onwards (Miller 1997: 1). In 2006, the MA became a strand of the Textile Conservation Centre's Museums and Galleries programme, ${ }^{4}$ a move that is testament to the strong connections that had developed by this point between the heritage sector and the study of historic dress and fashion (Taylor 2002: 272; for a recent example of museum and academic collaboration see Clynk and Peoples 2015). After major strategic changes at the University of Southampton in 2009, however, the Textile Conservation Centre moved to the University of Glasgow in 2010 and combined with the existing Technical Art History programme to form the new Centre for Textile Conservation and Technical Art History. The opportunity to establish a centre that would become home to two unique postgraduate degrees in the country, Textile Conservation and Technical Art History, was a 
strong motivator for the Glasgow move, and for the associated History of Dress and Textiles degree, it offered the chance to establish the first programme of its kind in Scotland.

\section{Present: the MLitt at the University of Glasgow}

Contemporary textile and costume design has a strong undergraduate presence in Scotland (for example, at Edinburgh College of Art, Heriot-Watt University, Duncan of Jordanstone College of Art and Design and The Glasgow School of Art) and the study of historic dress and fashion plays an important role on these programmes. The establishment of a postgraduate programme focussing solely on dress and textile histories, however, marked a new stage in the study, understanding and interpretation of historic dress and textiles north of the border. Given the growth of fashion studies and fashion theory at the turn of the twenty-first century, this move could have precipitated a complete change in approach and title, but the programme was re-branded just slightly to 'Dress and Textile Histories', both as a link to its Winchester predecessor and as a signal of its remit, particularly in relation to the terminology debates mentioned above. 'Dress history', for instance, is generally considered to be an inclusive term, one which encompasses fashion and utility (although they are not necessarily mutually exclusive), the unique and the everyday (Nicklas and Pollen 2015: 2). A prime example is the work of John Styles, which explores and analyses the everyday fashion and dress of eighteenth-century England (Styles 2008). Although definitions of 'fashion' have recently expanded to include 'dress, appearance and style' (Rocamora and Smelik 2016: 2), it can also be argued that the term is inextricably linked to notions of change: to be in fashion requires certain clothes at a certain time and so not all clothing can be considered 'fashion' or 'fashionable' (Nicklas and Pollen 2015: 2). The term 'dress and textile histories' was thus chosen for the new MLitt as it not only encompasses the notion of fashion but also allows consideration of the everyday and the extraordinary, component parts and complete outfits, manufacture and dissemination, dressing the body and dressing the interior, and lastly cloth as a two-dimensional textile and three-dimensional clothing.

These debates have extended to consideration of the methodological differences between fashion studies and dress history (McNeill 2010; Nicklas and Pollen 2014: 2; Granata 2012: 77). Giorgio Riello, for example, recently proposed a hybrid methodological approach that he termed 'the material culture of fashion', combining the centrality of artefacts often associated with dress history, with the theoretical and sometimes abstract approaches traditionally linked with fashion studies (Riello 2011). The decision to use the term 'dress and textile histories' at Glasgow, therefore, relates to this 'hybrid' approach, allowing flexibility in terms of the use of theoretical or empirical approaches, or, importantly, a combination of the two. Following closely in the footsteps of its predecessor, the Glasgow MLitt programme draws on curatorial practice, object-based and archival research to explore the production, use and meaning of dress and textiles in historical contexts. Using a combination of classroom-based teaching, off-campus site visits and self-directed learning, students are introduced to the fundamental yet varied aspects and ways dress and textile histories can be studied and used; it is thus an example of how Riello's 'material culture of fashion' can be put into practice. It incorporates art historical approaches, social history, semiotic theory, object and archivalbased experiences. Although based in the History of Art subject area, the programme is inherently interdisciplinary, drawing on the expertise of independent researchers, university academics from archaeology, economic and social history, fashion theory, museum studies and conservation science, as well as curators, costume designers, textile practitioners and heritage workers. Students also have the opportunity to study alongside peers from textile conservation, technical art history, art history and the wider humanities, encouraging interdisciplinary discussion and knowledge exchange from an early stage in their careers. While this is not quite the 'healthy disregard for theoretical boundaries' that Jonathan Faiers sees as being 'increasingly relevant to the advancement of our field today' (Faiers 2015: 31), the breadth and depth of the dissertation topics chosen by previous students for the final 
component of their studies demonstrates how consideration of historic dress and fashion can be interpreted in multifarious ways. Past dissertation topics, for instance, have included: a study of the use of jewels in the court of James V of Scotland, based on knowledge of current and historic jewellery making techniques and archival research; an in-depth object-based study of an early twentieth-century capsule collection in Glasgow Museums; and the examination of Doc Martens as expressions of sub-cultural identity in 1990s' Britain based on oral testimony and fashion theory.

Central to the programme in particular and to the development of dress history and fashion studies in general, is the role and importance of the object in developing understanding and knowledge of the field. First advocated in Britain by dress history pioneers Doris Langley Moore and James Laver (see Faiers 2015: 19-22), the mantle has more recently been taken up by Lou Taylor (Taylor 2013: 40) and Valerie Steele for fashion history (Steele 1998), amongst others. The centrality of objects to dress history has not always been widely accepted though; as noted by Taylor the two principal spheres of research in dress and textile histories - museums and academia - have, in the past, disagreed over the utility and appropriateness of object-based study (Taylor 2004). A conference organised in 1997 by Anthea Jarvis to celebrate the 50 th anniversary of Manchester's Gallery of Costume, and an associated special issue of Fashion Theory highlighted this issue of a methodological divide. John Styles, for example, called for 'not a crude pooling of approaches' but a 'willingness to monitor and reflect' on the different ways in which dress and textile history can be studied and understood (Styles 1998: 388). While collaboration between universities and museums has thankfully increased since 1998, the decision to appoint a subject specialist curator from Glasgow Museums as the first programme convenor of the MLitt programme in 2011 was still a pioneering move. This immediately signalled that collections-based research was embedded in all of the taught courses offered, from single objects for each student to research for their methodology essays to the use of capsule collections for larger research projects. For students, the opportunity to see, touch and examine an extant piece of historic fabric or garment is one of the most emotive means of encouraging empathy with a past person or society, something that the study of dress and textile history is extremely effective at (Gordon 2013). Similarly, the 'material turn' or 'renewed materialism' has also featured in recent approaches to fashion studies, with a focus on agency through things demonstrating how the theoretical and practical boundaries are becoming increasingly blurred (Rocamora and Smelik 2016: 12-4; Riello 2011: 3).

While the relationship between academic and curatorial practice is improving, it is also constantly evolving, a factor that is in no small part due to the shifting attitudes to museums in general and dress and fashion history in particular (Breward 2008). Continued collaboration between students, the dress and textile historians of the future, and museums is thus vital. For the MLitt in Dress and Textile Histories, the close relationship with Glasgow Museums, whose collections range from medieval tapestries to 1960s paper dresses, not only offers the chance for object-based study, it also provides the opportunity for students to contribute to Glasgow Museums' research, exhibition and public outreach programmes. For example, student's object-based work is added to the museums' objects files and referenced on the collections management system, enabling their research to be immediately available to museum staff and increasingly to the public as more records are added to the online database, Collections Navigator. ${ }^{5}$ Several items displayed in A Century of Style: Costume and Colour 1800-1899, an exhibition at Kelvingrove Art Gallery and Museum in 2015-2016, were researched by students or mounted by student volunteers, whilst stories initiated and researched by MLitt students on work placements will contribute to the Burrell Refurbishment project. This is a clear example of what Christopher Breward has noted as being the added value to "exhibition and gallery projects when both partners [academic and museum] are open to the shared benefits and learning experiences that accrue for all stakeholders' (Breward 2008: 87). For the student stakeholders the opportunity to work in and with the museum environment, and see their work be valued in this context, can be an important step in their personal and professional development. 
Other collaborative relationships have developed through student work placements, site visits and research projects with institutions across Scotland, many of which are recognised as nationally significant collections under the Recognition Scheme of Museums Galleries Scotland, such as the Paisley Shawl Collection at the Paisley Museum and Art Gallery and the Singer Sewing Machine Collection held by West Dunbartonshire Council. ${ }^{6}$ Building on the existing relationship between dress history, costume design and the performing arts, students are also introduced to areas where knowledge of dress and textile histories can be applied beyond the museum sector, with guest lectures from costume designers for film and television, or visits to costume departments of theatre and opera companies. Study visits serve multiple purposes: they introduce students to a specific collection or object, and they broaden students' understanding of the different ways in which dress and textile histories can be used and applied, from inspiration for costume design, to the technical and logistical aspects behind the design and mounting of a costume display, such as the new Fashion and Style gallery at the National Museum of Scotland, Edinburgh (opened 2016), or the Europe 1600-1815 Galleries (opened 2015) at the Victoria and Albert Museum (V\&A), London. Seeing dress and textile histories in action, furthermore, through the eyes of the professionals that are working with them, is equally valuable and insightful for the students' career planning and networking. The challenge, however, as it is for all institutions with similar programmes, will be in maintaining these links and projects in an era of increased pressure on staffing and finances.

As mentioned above, an important signifier for the MLitt programme is the consideration of both cloth and clothing, incorporating study of 2-D and 3-D pieces, visual representations and documentary evidence. Not only does this maintain the connection with the previous Winchester programme but importantly it also helps make a virtue of the MLitt programme's new geographic location. As noted, until relatively recently 'fashion' as a concept was considered applicable only to Western society (Mora et al. 2014) but even within the Western paradigm there are areas that have received less attention from dress and textile histories and fashion studies. Scottish dress, textiles and fashion are topics, for instance, that are understudied in comparison with its southern neighbour and richer European counterparts. The rich textile and clothing heritage of Scotland has thus helped to shape the structure of the core and optional courses. Chronologically the focus is on pre-twentieth century history, which not only draws on the strengths that the local and national institutions have to offer such as the industrial textile heritage of the west of Scotland, but also helps to distinguish the programme from some of the courses on offer in England. This also plays on one of the wider virtues of dress and textile history and fashion studies, that the study of a particular theme or aspect can be used to understand wider social, cultural and economic contexts. While the production of printed cottons in West Dunbartonshire may seem parochial, for instance, its reach and ramifications for understanding the role of Scotland and Britain in wider design history, industrial production and fashion, are much greater.

Understanding such relationships relies on both object and archive-based research and students are encouraged to engage with both from an early stage (Taylor 2002). While digitisation has made access to certain documentary source types much easier, this is not without its problems and as with surviving garments it is important that students have the opportunity to search for and see these items first hand as much as possible (Riello 2011: 7). The Scottish Business Archive, held in the University of Glasgow Archives, contains records for Scottish based textile manufacturers dating back to the eighteenth century, as well as records for the House of Fraser department store and all its subsidiaries nationwide. ${ }^{7}$ These collections provide extensive concrete evidence of the complex networks of production and consumption in textiles, dress and fashion. Other important archival collections include Glasgow City Archives at the Mitchell Library, and national collections in Edinburgh, such as the National Records Scotland and the National Library of Scotland, are also easily accessible. 
With access to archival collections that range from personal documents to industrial records, historical dress and textiles from local examples to global trends can be studied.

The establishment of the programme in 2011 also coincided with a resurgence in interest in Scottish dress and textiles by universities and cultural institutions. In 2010 the V\&A announced that Dundee would become home to the V\&A Museum of Design (due to open 2018) with a focus on the Scottish and global design exchange heritage, of which textiles obviously play a key role. Similarly, the opening of the new Fashion and Style Gallery at National Museums Scotland, Edinburgh in 2016, is an important example of how the display and interpretation of historic dress and modern design can be incorporated into a single space. Collaborative research projects and networks between Scottish universities and museums are increasing, demonstrating the potential vitality of Scottish dress and textile histories for research, recreation and design inspiration: examples include research projects based at the University of Edinburgh and National Museums Scotland (2011-13) which explored the links between design, production and fashion dissemination, ${ }^{8}$ and the ReINVENT (2013-4) and ReCREATE (2014-5) networks run by the University of Glasgow and National Museums Scotland, which brought together academics, heritage institutions, independent researchers and textile practitioners to highlight areas of current interest and research in the Scottish textile heritage.

As part of a research-led institution, furthermore, the content of the MLitt programme at Glasgow reflects the importance of cross-institutional collaboration. From the opening of the Centre for Textile Conservation and Technical Art History research networks that bring together faculty members, independent researchers, curators, doctoral students and postdoctoral scholars, have been at the fore, encouraging collaboration between the arts and the sciences on a range of dress and textile-related topics from monitoring historic tapestries to a study of Pacific bark cloth. ${ }^{9}$ Additionally, recent and ongoing projects based in the History department, such as one on historic knitting and doctoral work on the history of the Singer sewing machine factory in Clydebank, have involved graduates of the MLitt programme. ${ }^{10}$ It is hoped that the wider institutional collaboration and cooperation between the University and the city, which became manifest in the Kelvin Hall project with the rehousing of various collections from Glasgow Museums, the University of Glasgow's Hunterian Museum and Art Gallery and the National Library of Scotland under one roof along with dedicated teaching and learning space, will further foster such projects. Combined with the ever-present regional and local interest in clothing and textile production, the research and museum culture regarding fashion, dress and textiles in Scotland is vibrant and expanding, providing exciting opportunities for students, for the programme and for the field of dress and textile histories in general.

\section{Future: Meeting Challenges and Furthering Research}

The wider Scottish context for dress and textile histories is thus hopeful, but as with any further or higher education programme, the MLitt in Dress and Textile Histories faces both general and subject/field-specific challenges. With regards to the former, this is not the place to discuss the changing political situation and the wider impacts this has on university education and the arts in general but the potential upheaval and uncertainty for future students and graduates should still be acknowledged and will be something that all degree providers are cognizant of. Perhaps more within the providers' control is the fact that they have a fundamental responsibility to ensure that their students graduate with transferable skills and competencies; ${ }^{11}$ it is not enough to provide students only with subject-specific skills and attributes, particularly when career opportunities in the culture and heritage sector, for instance, are limited. The interdisciplinary potential of dress and textile history is an advantage here and the development and nurturing of transferable skills, such as good written and verbal communication, perseverance and professional attitudes are an inextricable element of the education process. It is no surprise, therefore, that work placements, offered by institutions on a variety of projects that range from object cataloguing, preventive conservation, to community 
engagement, are one of the most popular courses offered as part of the MLitt. The support, work and dedication of these institutions and their staff is vital to any programme that wishes to explore dress and textile history or fashion studies, but as noted above all such programmes face the identical challenge of maintaining such connections under increased financial, staffing and time constraints.

The interdisciplinary nature of dress and textile histories, while a boon in many respects (Taylor 2013), is, however, also the source of a number of challenges. From a practical, course organisation perspective, for instance, it needs to be taken into account that it attracts students and scholars from increasingly diverse academic backgrounds and training (Nicklas and Pollen 2015: 3; Granata 2012). Cohorts on the MLitt programme since 2011, for example, have included students with first degrees in English literature, fashion business, fashion journalism, history, French, business studies and museum studies; and applicants come with practical experience of fashion or historic reconstruction, curatorial skills and interests, as well as with the desire to pursue further research or careers in the heritage sector. Similarly, students from the United Kingdom have been joined by peers from Europe, Australia, Canada, Chile, India, New Zealand, Switzerland, Taiwan and the United States, to name just a few. From a peer-learning perspective such diversity is a great advantage at all levels of higher education; but courses, training and assessments do need to take into account how to accommodate and expand the wide variety of pre-existing skill-sets while also focusing on the increasingly important and ever-present issue of employability and the development of transferable skills that are applicable in a more or less global setting. Assignments are designed to reflect this and embrace theory and practice in the form of exhibition reviews, project proposals for museums, group and individual presentations based on object-based and archival research, and work placement portfolios. These assignments develop skills in collating and interpreting large amounts of primary and secondary information, the formulation and presentation of original arguments and the questioning of existing ones. Such skills are useful in areas that are dress and textile specific, such as doctoral study, museums and other heritage institutions, or costume design/making for film, television or stage, as well as being transferable to sectors beyond dress and textile histories in Britain and further afield.

Interdisciplinarity also poses challenges for the students, and questions voiced by Lou Taylor are particularly pertinent to the running of this programme at the University of Glasgow. She notes that

No one can possibly be skilled in every one of these academic fields [relating to fashion studies or dress history], each of which has its own sets of specific critical approaches, interests, and standpoints, so where does this leave the bewildered incoming student? What critical stance does the drowning researcher leave in, without overconfusing the story, and what can she/he leave out without compromising it? (Taylor 2013: 23)

These are ever-present questions and challenges for the students themselves, further heightened by the pressure of a one-year programme and a competitive job market. One option is, as Jonathan Faiers argues, is for dress history and dress historians to be less concerned with 'seeking definitions or alliances' between disciplines, and instead 'embrace indeterminacy and fluctuation' (Faiers 2015: 18). While the terms 'indeterminacy' and 'fluctuation' might strike as much fear in a student's heart as the daunting prospect of being an expert in all things and methodologies, there is something to be said for the flexibility that dress and textile histories encourage. The purpose of the MLitt, therefore, remains to introduce students to the different ways of thinking about, approaching and using dress and textile histories, a vital process especially when dealing with students who might not necessarily have an art history or dress history background. By no means is it expected that students should become specialists in all the different relevant academic fields, but an awareness of the virtues and pitfalls of the different approaches can help them make informed decisions as to how they wish to pursue their own research. The success of this is evident in the scope of dissertation topics and 
methodological approaches that are employed noted above, and in the increasing number of graduates who have developed doctoral projects, both at Glasgow and at other institutions. The doctoral path also contains many challenges, not least the paucity of available funding, and yet it could be argued that the interdisciplinary potential of dress and textile history gives it an edge in this area. Graduates of the programme are currently pursuing doctoral work in the subject areas of history, business history, history of art and medieval history. Two doctoral projects in particular are worth mentioning due to their interdisciplinary nature and for their success in receiving funding from national funding bodies. The first is an examination of the much understudied twentieth-century fashion industry in Glasgow, drawing on business history and fashion theory; and the second, jointly supervised by the University of Glasgow and the Glasgow School of Art, is utilising the Stoddard-Templeton collections to explore the relationship between technological advances and design in carpet manufacture. Both projects are being undertaken by graduates of the MLitt programme and both work closely with public and private object and archival collections. The presence of the programme has also inspired collaborative relationships across the University, such as the development of a $\mathrm{PhD}$ project due to start in 2017 that draws on Hispanic studies, accounting and business history, and dress and textile history to explore the Scottish manufacture of textiles for the Spanish-speaking world. This stems from a staff initiative to develop cross-faculty collaboration in supervision and project development. It is these projects, pursued by graduates of the programme and staff associated with it and which rely on cross-institutional collaboration and engagement that are paving the way for future students of dress and textile histories.

Lou Taylor recently wrote that when it comes to dress history and fashion studies, the 'horizons seem limitless, and there is no end to research possibilities in sight, with much still to be done' (Taylor 2013: 40). This is very much the ethos by which the MLitt in Dress and Textile Histories at the University of Glasgow is run. The fact that dress and textile histories can be interdisciplinary, but equally they do not have to be, is part of their appeal (Faiers 2015: 15-32). Thanks to the work of scholars such as Taylor, Steele, Styles and Breward, to name just a few, the challenge is now not so much convincing others of the importance, relevance and significance of such studies, it is ensuring that future generations of students are aware of all those who have pioneered this ever-increasing and exciting field. Armed with this information, they can blaze their own trail.

\section{Acknowledgements}

The authors would like to thank Prof Frances Lennard, University of Glasgow, Prof Lesley Miller, University of Glasgow and V\&A, and the editors and reviewers for their comments and advice on earlier versions of this article.

\section{REFERENCES}

Breward, C. (2008), 'Between the Museum and the Academy: Fashion Research and its Constituencies', Fashion Theory: The Journal of Dress, Body and Culture, 12:1, pp. 83-93.

Clynk, J. and Peoples, S. (2015), 'All Out in the Wash: Convict Stain Removal in the Narryna Heritage Museum's Dress Collection', in C. Nicklas and A. Pollen (eds), Dress History: New Directions in Theory and Practice, London: Bloomsbury Academic, pp. 49-64.

Cumming, V. (2004), Understanding Fashion History, London: Batsford.

Faiers, J. (2015), 'Dress Thinking: Disciplines and Indisciplinarity', in C. Nicklas and A. Pollen (eds), Dress History: New Directions in Theory and Practice, London: Bloomsbury Academic, pp. 15-32. 
Francks, P. (2015), 'Was Fashion a European Invention?: The Kimono and Economic Development in Japan', Fashion Theory: The Journal of Dress, Body and Culture, 19:3, pp. 331-361.

Gordon, B. (2013), Textiles: The Whole Story: Uses, Meaning, Significance, London: Thames and Hudson.

Granata, F. (2012), 'Fashion Studies In-Between: A Methodological Case Study and an Inquiry into the State of Fashion Studies', Fashion Theory, 16:1, pp. 67-82.

Jarvis, A. (ed.) (1998), Special Issue, Fashion Theory: The Journal of Body, Dress and Culture, 2:4, pp. 299-392.

O’Neill, G. and McMahon, T. (2005), 'Student-centred learning: what does it mean for students and lecturers?', in G. O'Neill, S. Moore and B. McMullin (eds), Emerging Issues in the Practice of University Learning and Teaching, Dublin: AISHE, pp. 27-36.

McNeil, P. (2010), 'Conference Report: "The Future of Fashion Studies”, Fashion Theory, 14:1, pp.105-110.

Miller, L. (1997), 'A List of MA Dissertations Written by the Students of the History of Textiles and Dress, Winchester School of Art', Costume, 31:1, pp. 111-112.

Mora, E., Rocamora, A., and Volonté, P. (2014), 'The Internationalization of Fashion Studies: Rethinking the Peer-reviewing Process' in International Journal of Fashion Studies, 1:1, pp. 3-17.

Nicklas, C. and Pollen, A. (2015), 'Introduction - Dress History Now: Terms, Themes and Tools', in C. Nicklas and A. Pollen (eds), Dress History: New Directions in Theory and Practice, London: Bloomsbury Academic, pp. 1-14.

Riello, G. (2011), 'The Object of Fashion: Methodological Approaches to the History of Fashion', Journal of Aesthetics and Culture, 3, pp. 1-9.

Rocamora, A. and Smelik, A. (2016), 'Thinking Through Fashion: An Introduction', in A. Rocamora and A. Smelik (eds) Thinking Through Fashion: A Guide to Key Theorists, London: I.B. Tauris, pp. $1-27$.

Steele, V. (1998), 'A Museum of Fashion is More Than a Clothes-Bag', Fashion Theory: The Journal of Dress, Body and Culture, 2:4, pp. 327-336.

Styles, J. (1998), 'Dress in History: Reflections on a Contested Terrain', in Fashion Theory: The Journal of Dress, Body and Culture, 2:4, pp. 383-392.

Styles, J. (2008), The Dress of the People: Everyday Fashion in Eighteenth-Century England, New Haven \& London: Yale University Press.

Taylor, L. (2002), The Study of Dress History, Manchester: Manchester University Press.

Taylor, L. (2004), Establishing Dress History, Manchester: Manchester University Press. 
Taylor, L. (2013), 'Fashion and Dress History: Theoretical and Methodological Approaches', in S. Black, A. de la Haye, J. Entwistle, A. Rocamora, R.R. Root, and H. Thomas (eds), The Handbook of Fashion Studies, London: Bloomsbury, pp. 23-43.

\footnotetext{
${ }^{1}$ There are a number of opportunities for students to study dress and fashion history at undergraduate level, particularly in England, including degrees such as the BA(Hons) in Fashion Communication: Fashion History and Theory at Central St Martins http://www.arts.ac.uk/csm/courses/undergraduate/ba-fashion-communication-fashion-history/. Accessed 10 January 2017. See also the BA(Hons) in Fashion and Dress History at the University of Brighton https://www.brighton.ac.uk/courses/study/fashion-and-dress-history-ba-hons.aspx. Accessed 10 January 2017. For information on postgraduate degrees offered by the Courtauld Institute and London College of Fashion, see http://courtauld.ac.uk/research/sections/history-dress and http://www.arts.ac.uk/fashion/. Accessed 24 January 2017.

${ }^{2}$ Further information about the MLitt in Dress and Textile Histories can be found here: http://www.gla.ac.uk/postgraduate/taught/dresstextilehistories/. Accessed 24 January 2017.

${ }^{3}$ The MLitt is a Master of Letters in order to differentiate from the Scottish four-year undergraduate degrees in arts and humanities, which are Masters of Arts (MA).

${ }^{4}$ For more information on the Textile Conservation Foundation and its history, see http://www.tccfoundation.org.uk/. Accessed 24 January 2017.

${ }^{5}$ The first phase of Glasgow Museums' online database consisted mainly of archive level descriptions with only key objects attached. The second phase is due to be published in summer 2017 with a framework to enable all collections objects to be published online.

${ }^{6}$ The Recognition Scheme promotes and protects nationally significant museum and gallery collections in Scotland. See, www.museumsgalleriesscotland.org.uk/accreditation-recognition/recognition-scheme/. Accessed 24 January 2017.

${ }^{7}$ See http://www.gla.ac.uk/services/archives/collections/business/. Accessed 24 January 2017.

8 'Colouring the Nation: The Turkey Red Printed Cotton Industry in Scotland' was a collaborative project between the University of Edinburgh and National Museums Scotland, 2011-2013. See http://www.nms.ac.uk/collectionsresearch/our-research/highlights-of-previous-projects/colouring-the-nation/. Accessed 21 June 2017.

${ }^{9}$ The inaugural research network was a two-year project funded by the Getty Foundation, involving participants from textile conservation, dress and textile histories and technical art history, culminating in a conference and associated publication in 2012: R. Gordon, E. Hermans and F. Lennard (eds) (2014), Authenticity and Replication: The 'Real Thing' in Art and Conservation: Proceedings of the International Conference Held at the University of Glasgow, December 2012, London: Archetype. Other projects include a Leverhulme Trust Research Grant project 'From the Golden Age to the Digital Age: Modelling and Monitoring Historic Tapestries', and the collaborative research networks ReCREATE and ReINVENT, run by the University of Glasgow and National Museums Scotland. See:

http://www.gla.ac.uk/schools/cca/research/instituteofarthistory/projectsandnetworks/recreate/ and http://www.gla.ac.uk/schools/cca/research/instituteofarthistory/projectsandnetworks/reinvent/. Accessed 24 January 2017.

${ }^{10}$ For more information see the Knitting in the Round webpage

http://www.gla.ac.uk/schools/humanities/research/historyresearch/researchprojects/knittingintheround/. Accessed 8 January 2017.

${ }^{11}$ This relates to the University of Glasgow graduate attributes matrix which identifies three key areas where a university education can make a contribution: academic, personal and transferable. http://www.gla.ac.uk/media/media 183776 en.pdf/ Accessed 8 January 2017.
} 